\title{
Self-sampling and HPV testing or ordinary Pap-smear in women not regularly attending screening: a randomised study
}

\author{
I Wikström*,', M Lindell', K Sanner' and E Wilander ${ }^{2}$ \\ 'Department of Women's and Children's Health, Uppsala University, S75I 85 Uppsala Sweden; ²Department of Genetics and Pathology, Uppsala \\ University, 575185 Uppsala, Sweden
}

BACKGROUND: Most women with cervical cancer have not participated in Pap-smear screening. Self-sampling of vaginal fluid in combination with high-risk HPV testing may be a method to increase the attendance rate.

METHODS: A total of 4060 women, 39-60 years old, who had not attended the organised Pap-smear screening for 6 years or more were randomised into two equal groups. A study group was offered to self-sample vaginal fluid (Qvintip) at home and/or recommended to attend the Pap-smear screening. The collected fluid after self-sampling was examined for the presence of high-risk HPV (Hybrid Capture 2 method). Controls were only recommended to attend the Pap-smear screening. The end point was a histological identification of CIN2-3.

RESULTS: The participation rate was 39\% (77I out of 2000) in the self-sampling group and $9 \%$ (I 88 out of 2060) in the conventional cytology $(P<0.001)$. The number of histological CIN2 -3 alterations detected was $0.4 \%$ ( 8 out of 2000) among women offered self-sampling of vaginal fluid and $0.07 \%$ (3 out of 4060) in women offered Pap-smears. The odds ratio (OR) for offering self-sampling and HPV testing instead of Pap-smear screening for detection of CIN2-3 was OR =5.42 (95\% Cl: 1.30-31.8).

CONCLUSION: Offering self-sampling of vaginal fluid followed by a high-risk HPV test was considerably more effective for detection of histological CIN2-3 lesions in comparison with offering Pap-test in a midwife reception in women not regularly attending organised screening.

British Journal of Cancer (201 I) 1 05, 337-339. doi:I0.1038/bjc.201।.236 www.bjcancer.com

Published online 5 July 2011

(c) 20II Cancer Research UK

Keywords: cervix; human papilloma virus; self-sampling; cytological screening

For documentation of the efficiency of organised Pap-smear screening for cervical cancer, nationwide audits are valuable. An investigation in Sweden showed that the majority of women (65\%) with cervical cancer had not attended the organised Pap-smear screening, and around $25 \%$ developed cancer despite a regular participation due to the occurrence 'false-negative' smears (Andrae et al, 2008). A number of 'false-negative' smears indicates a low sensitivity of Pap-smear screening. A recent study, using primary screening with a high-risk HPV test for identification of histological CIN2-3 lesions, showed that the sensitivity of a single Pap-smear to detect CIN2-3 alterations is around $50 \%$, also indicating a low sensitivity of cytological screening (Ronco et al, 2010).

To increase the participation rate and decrease the incidence of cervical cancers in the County of Uppsala, women not attending organised Pap-smear screening were, since the year 2006, offered self-sampling of vaginal fluid at home in combination with a highrisk HPV test (Stenvall et al, 2006; Sanner et al, 2009). Initially, during 2006-2007, a pilot study comprising 600 women not attending Pap-smear screening was performed (Stenvall et al, 2006). These women were not included in the present investigation. The HPV-positive women are recommended a follow-up in a gynaecological surgery (colposcopy clinic) or a midwife reception

*Correspondence: Dr I Wikström; E-mail: ingrid.wikstrom@kbh.uu.se Received 24 February 2011; revised 24 May 201 I; accepted 31 May 20I I; published online 5 July 201 I (family planning clinic). Preliminary results indicate that the selfsampling method is an attractive alternative for women who choose not to participate in the organised screening. Around $40 \%$ of women not regularly attending a midwife reception for smear sampling accept the home sampling method and most women attending a midwife reception for smear collection would prefer to collect vaginal fluid at home, if they were offered that possibility (Wikström et al, 2007a). In addition, the risk for obtaining 'falsenegative' results is minimal (Ronco et al, 2010).

In this study, women not regularly attending in the organised Pap-smear screening programme were randomised into two groups of equal size. One group was offered ordinary Pap-smear screening and the other group the possibility of self-sampling of vaginal fluid at home as an alternative to Pap-smear screening. The main outcome measures of the study were the attendance rate and the identification of histological CIN2 -3 lesions in both groups.

\section{MATERIALS AND METHODS}

A total of 4060 women, 39-60 years old, who had not participated in the organised Pap-smear screening for 6 years or more were collected from the local data base at the Department of Pathology and Cytology, Uppsala University Hospital, Sweden in January 2007.

The women were randomly divided into a study group of 2000 women and a control group of 2060 women. In the study group, all women were offered self-sampling at home with a self-sampling 
device (Qvintip, Aprovix AB, Uppsala, Sweden) as an adjunct to organised Pap-smear screening. In the control group, women were only advised to participate in Pap-smear screening. In the organised Pap-smear screening, women 25-60 years old are invited for smear sampling every third year. Women, who choose not to attend receives additional invitation letters once a year.

All 2000 women in the study group were sent an information letter by post, and after a few days, they received the self-sampling device, instructions how to perform the sampling of vaginal fluid and to send the collected material to our laboratory in the enclosed, prepaid return letter. The procedure was free of charge and the women were also reminded in a second invitation. At the laboratory, the samples were used for high-risk HPV testing with the Hybrid Capture 2 (hc2) method (Qiagen AB, Solna, Sweden). The HPV test identifies 13 high-risk HPV types $(16,18,31,33,35$, $39,45,51,52,56,58,59$ and 68). The hc2 method can detect HPV DNA concentrations over $1 \mathrm{pg} \mathrm{ml}^{-1}$, which is proportional to the light emission of the positive control and corresponds to $5000 \mathrm{HPV}$ genomes per specimen in the well. The results of the HPV test were mailed to all women participating in the study. All information on women in the study group was collected in the database of the department, together with records on the Pap-smear screening and histopathological examinations.

The women who were high-risk HPV positive were recommended a follow-up examination at a midwife reception or a gynaecological surgery. In women examined by a gynaecologist, a biopsy from the cervix was obtained, whereas in women attending a midwife reception a repeated cytology, often in combination with a cervical sample for HPV analysis, was taken. All women offered self-sampling at home were also offered to participate in the organised Pap-smear screening.

The women in the control group were invited to a midwife reception for collection of cervical smear, within the framework of the organised screening programme. Women with ASCUS or CIN1 alterations observed in the screening were called for re-examination at the midwife reception and women with CIN2-3 cell changes were admitted to a gynaecological reception for colposcopy and cervical biopsy. The women paid 100 SEK (around 10 EUR) only for the first Pap-smear collection.

At the end of December 2007, all women who had performed self-sampling of vaginal smear at home in combination with a high-risk HPV test, and all women in the study and control groups participating in the Pap-smear screening were identified. Women who were HPV positive or showed abnormal cytology (ASCUS CIN3) were followed until December 2009. The end point of the study was a histopathological CIN2 - 3 lesions observed in cervical biopsies or after cervical cone resection.

\section{RESULTS}

In the study group, 679 out of 2000 women (34\%) accepted to perform self-sampling of vaginal fluid at home and send the collected material to our laboratory for high-risk HPV analysis, whereas 100 out of 2000 women (5\%) preferred to attend a midwife reception for Pap-smear sampling. In total, 779 out of 2000 women $(39 \%)$ in the study group participated in the screening. Among the controls, 188 out of 2060 women (9\%) attended the Pap-smear screening programme. The difference in attendance rate between the two groups was strongly significant $(P<0.001$; Table 1$)$.

A high-risk HPV-positive reaction was recorded in 41 out of 679 women $(6.0 \%)$ performing self-sampling. The prevalence of HPV infection decreased with age, it was $7.5 \%$ (23 out of 305$)$ in women $39-49$ years old and $4.8 \%$ (18 out of 374 ) in women aged $50-60$ years.

Of HPV-positive women, 24 out of 41 (59\%) visited a gynaecological surgery, directly or via a midwife reception, for further examination including colposcopy and biopsy within 1-7 months after the collection of vaginal fluid. A total of 16 out of 41
Table I Recruitment of 39- to 60-year-old women not attending organised cytological screening for more than 6 years by invitation for selfsampling of vaginal smear at home and/or Pap-smear screening (study group, 2000 cases) and offering only Pap-smear screening (control group, 2060 cases)

\begin{tabular}{lcc}
\hline Categories & Study group & Controls \\
\hline Total number of women & 2000 & 2060 \\
Self-sampling of vaginal fluid & 679 & 0 \\
Pap-smear screening & 100 & 188 \\
Not attending & 1221 & 1872 \\
Total number of participating women & $779 / 2000(39 \%)$ & $188 / 2060(9.1 \%) *$ \\
\hline$*<0.001$ & &
\end{tabular}

Table 2 Light microscopic morphology in 24 cervical biopsies of high-risk human papilloma virus-positive women

\begin{tabular}{lc}
\hline Light microscopy & Number of cases \\
\hline Normal & $12 / 24(50 \%)$ \\
CINI & $4 / 24(17 \%)$ \\
CIN2-3 & $8 / 24(33 \%)^{\mathrm{a}}$ \\
\hline
\end{tabular}

${ }^{\mathrm{a} O}$ One case with only cytological findings of CIN3.

(39\%) only visited a midwife reception. The compliance of the HPV-positive women was $98 \%$ (40 out of 41 ). One woman had moved out of the county and was not possible to reach.

The biopsies showed normal histology in 12 cases, CIN1 in 4 cases and CIN2-3 in 8 cases (Table 2). Women with CIN2-3 lesions were treated with cervical cone resection, whereas women with CIN1 and 4 women with normal histology and a persistent HPV-positive reaction were offered a continuous follow-up. Of the 16 women visiting only a midwife reception, 1 was HPV positive and 1 showed ASCUS. They were followed up, and in no case, a histological CIN2-3 was recorded.

A total of 100 women in the study group and 188 of the controls participated in the Pap-smear screening. Of these women, one cytological slide was not representative, one showed ASCUS, one CIN1 and three CIN2-3. The women with ASCUS were HPV negative, the women with CIN1 had a normal biopsy and the women with CIN2-3 were operated with cone resection, which histologically verified the CIN2 -3 lesions.

All 4060 women in the investigation were offered collection of Pap-smear at a midwife reception, and 288 chose to participate. Of the participating women, three were identified with histological CIN2 -3 on the cervix. A total of 2000 women were offered selfsampling of vaginal fluid at home in combination with HPV testing, and of 679 participating women, 8 had histological CIN2-3 lesions on the cervix. The odds ratio (OR) for identification of histological CIN2-3 lesions with the self-sampling at home method in comparison with Pap-smear screening was $\mathrm{OR}=5.42$ (95\% CI: 1.3-31.8; Table 3).

\section{DISCUSSION}

As mentioned in the introduction, non-attendance is the major problem in countries with an organised Pap-smear screening for cervical cancer (Bos et al, 2006; Andrae et al, 2008; Lindqvist et al, 2008). Although this fact has been known for many years, no simple method to increase the coverage to the cytological screening is available (Eaker et al, 2004; Oscarsson et al, 2008). However, combinations of different invitations are reported to increase the number of detected precursor lesions (Eaker et al, 2004).

The method of self-sampling of vaginal fluid at home seems to be an attractive alternative for the non-participating women. It is less time consuming and it offers a possibility to avoid the 
Table 3 Number of women with histological CIN2-3 lesions among women offered self-sampling of vaginal smear at home in combination with high-risk human papilloma virus testing and in women offered organised Pap-smear screening

\begin{tabular}{lcc}
\hline Categories & $\begin{array}{c}\text { Self-sampling } \\
\text { of vaginal fluid }\end{array}$ & Pap-smear \\
\hline Total number of women & 2000 & 4060 \\
Number of participating women & $679 / 2000(34 \%)$ & $288 / 4060(7.1 \%)$ \\
Number of women with CIN2-3 & $8 / 679(1.2 \%)^{\mathrm{a}}$ & $3 / 288(1.0 \%)$ \\
Number of CIN2-3/total number & $8 / 2000(0.4 \%)^{\mathrm{b}}$ & $3 / 4060(0.07 \%)^{\mathrm{b}}$ \\
of women & & \\
\hline
\end{tabular}

${ }^{\mathrm{a}}$ One case with only cytological findings of CIN3. ${ }^{\mathrm{b}}$ Odds ratio $=5.42$ ( $95 \%$ confidence interval: $1.30-31.8)$

gynaecological chair position. The HPV test is also about twice as sensitive as a Pap test to identify histological CIN2 - 3 lesions. Several studies have shown that $30-50 \%$ of women not attending midwife receptions for Pap-smear screening accept the self-sampling method (Stenvall et al, 2006; Sanner et al, 2009; Gök et al, 2010). In this study, $87 \%$ of the attending women preferred self-sampling when they had the possibility to choose between self-sampling and Pap-smear screening. The fact that the self-sampling alternative was free of charge has probably contributed to the high attendance rate in this group. However, among women visiting a gynaecological surgery, $90 \%$ explained that they would prefer self-sampling at home instead of Pap-smear collection at a midwife reception provided that this possibility was available (Wikström et al, 2007a).

Although there is a general interest in increasing the coverage of the organised Pap-smear screening, there are also some objections against the use of HPV tests in organised screening for cervical cancer. One main reason is that, despite the high sensitivity, the HPV test is considered to have a too low specificity (Wright et al, 2004; Meijer et al, 2009). A number of women will be identified with highrisk HPV infection but without any cytological alterations, and no method is available for treatment of the HPV infection.

However, it must be kept in mind that the prevalence of highrisk HPV infections decreases with age and in post-menopausal women HPV infections are almost as uncommon as cell alterations (ASCUS-CIN3) in the Pap-smear screening. Consequently, in women 50 years and older HPV tests are almost as specific as Papsmear screening (Wikström et al, 2007b; Sanner et al, 2009). Furthermore, the sensitivity of conventional cytology decreases markedly in post-menopausal women and most women with CIN2 - 3 lesions on the cervix display normal cytology (Gustafsson et al, 1995; Gyllensten et al, 2010). For that reason, self-sampling of vaginal fluid at home and HPV testing seems to be a reliable method to increase the attendance rate and also the sensitivity of the screening in countries with an organised Pap-smear screening programme. It is also indicated that self-sampling and HPV testing may be an attractive method for screening of menopausal women, an age category in which only around $20 \%$ of the maximal effect of Pap-smear screening remains and in which most women with cell alterations (ASCUS-CIN3) are high-risk HPV negative (Gyllensten et al, 2010).

A power analysis was performed. The number of participating women was however limited by the financial support for the study. The study population is too small to document differences in sensitivity between HPV and Pap-smear screening but it shows that self-sampling at home is an alternative to ordinary repeated calling of Pap-smear collection to non-responders.

\section{ACKNOWLEDGEMENTS}

The study was supported by the County Council of Uppsala and by the Medical Faculty of Uppsala University. The study was evaluated by the local ethic committee (Dnr2004:M-202 and 2009/001). Professor Pär Sparén, Department of Medical Epidemiology, Karolinska Institute, is acknowledged for randomisation of the material.

\section{Conflict of interest}

Erik Wilander is a minority shareholder in the company Aprovix AB, marketing Qvintip. All the other authors declare no conflict of interest.

\section{REFERENCES}

Andrae B, Kemetli L, Sparén P, Silfverdal L, Strander B, Ryd W, Dillner J, Törnberg S (2008) Screening-preventable cervical cancer risks: evidence from a nationwide audit in Sweden. J Natl Cancer Inst 100: 605-606

Bos A, Rebolj M, Habbema JD, van Ballegooijen M (2006) Nonattendance is still the main limitation for the effectiveness of screening for cervical cancer in the Netherlands. Int J Cancer 119: 2372 - 2375

Eaker S, Adami HO, Granath F, Wilander E, Sparén P (2004) A large populationbased randomized controlled trial to increase attendance at screening for cervical cancer. Cancer Epidemiol Biomarkers Prev 13: 346-354

Gustafsson L, Sparén P, Gustafsson M, Pettersson B, Wilander E, Bergstrom R, Adami HO (1995) Low efficiency of cytological screening for cancer in situ of the cervix in older women. Int J Cancer 63: 804-809

Gyllensten U, Lindell M, Gustafsson I, Wilander E (2010) HPV test shows low sensitivity of Pap screen in older women. Lancet Oncol 11: 509-510

Gök M, Heideman DA, van Kemenade FJ, Berkhof J, Rozendaal L, Spruyt JW, Voorhorst F, Beliën JA, Babovic M, Snijders PJ, Meijer CJ (2010) HPV testing on self collected cervicovaginal lavage specimens as screening method for women who do not attend cervical screening: cohort study. BMJ 340: c1040

Lindqvist PG, Hellsten C, Rippe A (2008) Screening history of women in Malmö with invasive cervical cancer. Eur J Obstet Gynecol Reprod Biol 137: $77-83$

Meijer CJ, Berkhof J, Castle PE, Hesselink AT, Franco EL, Ronco G, Arbyn M, Bosch FX, Cuzick J, Dillner J, Heideman DA, Snijders PJ (2009) Guidelines for human papillomavirus DNA test requirements for primary cervical cancer screening in women 30 years and older. Int $J$ Cancer 124: 516-520
Oscarsson MG, Benzein EG, Wijma BE (2008) Reasons for non-attendance at cervical screening as reported by non-attendees in Sweden. J Psychosom Obstet Gynaecol 29: 23-31

Ronco G, Giorgi-Rossi P, Carozzi F, Confortini M, Dalla Palma P, Del Mistro A, Ghiringhello B, Girlando S, Gillio-Tos A, De Marco L, Naldoni C, Pierotti P, Rizzolo R, Schincaglia P, Zorzi M, Zappa M, Segnan N, Cuzick J, New Technologies for Cervical Cancer screening (NTCC) Working Group (2010) Efficacy of human papillomavirus testing for the detection of invasive cervical cancers and cervical intraepithelial neoplasis: a randomised controlled trial. Lancet Oncol 11: 249-257

Sanner K, Wikström I, Strand A, Lindell M, Wilander E (2009) Selfsampling of the vaginal fluid at home combined with high-risk HPV testing. Br J Cancer 101: 871-874

Stenvall H, Wikström I, Wilander E (2006) Human papilloma virus testing of vaginal smear obtained with a novel self-sampling device. Acta Derm Venereol 86: $465-467$

Wikström I, Stenvall H, Wilander E (2007a) Attitudes to self-sampling of vaginal smear for human papilloma virus analysis among women not attending organized cytological screening. Acta Obstet Gynecol Scand 86: $720-725$

Wikström I, Stenvall H, Wilander E (2007b) Low prevalence of high-risk HPV in older women not attending organized cytological screening: a pilot study. Acta Derm Venereol 87: 554-555

Wright Jr TC, Schiffman M, Solomon D, Cox JT, Garcia F, Goldie S, Hatch K, Noller KL, Roach N, Runowicz C, Saslow D (2004) Interim guidance for the use of human papillomavirus DNA testing as an adjunct to cervical cytology for screening. Obstet Gynecol 103: 304-309. Review 